\title{
Diagnostic value of heparin-binding protein in the cerebrospinal fluid for purulent meningitis in children
}

\author{
Dan Ren ${ }^{1 \oplus \bowtie}$, Di Wu${ }^{2 \oplus}$, Fu Liu ${ }^{1 \oplus}$, Shuli Jiao ${ }^{1 \oplus}$, and $\mathrm{Yi} \mathrm{Wu}^{1 \oplus}$ \\ ${ }^{1}$ Department of Pediatrics, Mianyang Central Hospital, Mianyang, Sichuan, China \\ ${ }^{2}$ Department of Gynecology and Pediatrics, Hospital of PLA Unit 63820, Mianyang, Sichuan, China
}

\begin{abstract}
This study aimed to investigate the diagnostic value of heparin-binding protein (HBP) in the cerebrospinal fluid of children with purulent meningitis (PM). This study included 118 children with PM diagnosed at our hospital from January 2018 to January 2020, 110 children with viral meningitis (VM) and 80 children with suspected meningitis who were ruled out by cerebrospinal fluid (CSF) analysis during the same period. HBP and white blood cell (WBC) count in the CSF, and inflammatory factors, including C-reactive protein (CRP), tumor necrosis factor (TNF)- $\alpha$, and procalcitonin (PCT), were measured. Receiver-operator characteristic curves were used to analyze the predictive value of HBP, CRP, PCT, and TNF- $\alpha$ levels in the diagnosis of PM by CSF analysis. HBP levels in the CSF of children with PM were higher, while the CRP and serum PCT and TNF- $\alpha$ levels were elevated in all groups $(\mathrm{P}<0.05)$. In addition, HBP levels in the CSF were more accurate for the diagnosis of PM than traditional diagnostic indexes. HBP levels in the CSF can be used as an important reference for early diagnosis of PM.
\end{abstract}

Key words: Pyogenic meningitis; HBP; CRP; PCT; TNF- $\alpha$

\section{Introduction}

Purulent meningitis (PM) is an infection of the meninges caused by a purulent bacterial infection and a common purulent infection of the central nervous system. It is more common in children, and some children can show a severe condition and die within $24 \mathrm{~h}$ if they are not treated in time. Frequently showing high fever, headache, vomiting, severe malaise, disturbance of consciousness, occasional convulsions, oliguria, or anuria, patients suffering from brain parenchymal damage quickly enter a coma, with frequent convulsions, hemiplegia, high blood pressure, dilated pupils on one side, lack of light reflex sign, and fixed eyeballs followed by respiratory failure and death. The incidence of PM has been increasing with the misuse of antibiotics (1), and the mortality rate has been reported to be $>40 \%$ in children (2). Diagnosis of the disease is difficult to confirm due to the lack of apparent specific early clinical manifestations, which contributes to a higher rate of disability (3) and seriously affects the daily life of patients and their families. Currently, the gold standard for the diagnosis of PM is cerebrospinal fluid (CSF) analysis (4). However, the long testing time and low accuracy have limited its clinical application. Therefore, early diagnosis of PM is crucial.
A study found that C-reactive protein (CRP), tumor necrosis factor (TNF)- $\alpha$, and procalcitonin (PCT) levels can be potential markers. However, their application in clinical diagnosis has some limitations (5).

Heparin-binding protein (HBP), which has azurophilic granules and is released by secretory vesicles of neutrophils, is a serine protease (6). It has been shown that HBP is involved in the development of a variety of inflammatory conditions and infections (7). In the early stages of the inflammatory process, eosinophilic granules and secretory vesicles secrete HBP, which acts by activating various types of cells (8), including monocytes, and leads to vascular leakage and edema formation (9). It has been shown that HBP is also secreted after polymorphonuclear cell exudation and promotes inflammatory responses (10). In a study from 2011, Linder et al. (11) describes HBP as a superior marker of bacterial meningitis in adults. The association between HBP levels in the CSF and the diagnosis of PM in children has not been reported. This study assessed the diagnostic value of $\mathrm{HBP}$ in patients with $\mathrm{PM}$, as well as non-PM, by comparing the expression levels of HBP with other biomarkers. 


\section{Material and Methods}

\section{Study subjects}

A total of 308 children who visited our hospital between January 2018 and January 2020 were enrolled in this study [ 118 children with PM (PM group), 80 children initially suspected of having meningitis but whose diagnosis was ruled out (CON group), and 110 children with viral meningitis (VM group)]. All patients' families were informed of the risks and signed informed consent forms. The ethics committee of Mianyang Central Hospital approved this study (ChiCTR1800015276). Children with PM and VM were selected strictly according to the inclusion and exclusion criteria. The inclusion criteria for PM were i) children with common symptoms of PM, including fever, irritability, vomiting, drowsiness, and impaired consciousness, and ii) positive bacterial cultures or smear test of the CSF. The inclusion criteria for VM were i) children with a final diagnosis of VM based on electroencephalogram, magnetic resonance imaging features, and serological tests, and ii) no detection of bacteria in the CSF culture or negative results in the smear test.

The exclusion criteria were i) children with congenital neurological malformations, ii) children with intracranial hemorrhage and septic infection, and iii) children with inherited metabolic disorders.

\section{Data collection}

The enrolled patients underwent an initial clinical assessment, including demographics, vital signs (heart rate, respiratory rate, blood pressure, and arterial oxygen saturation), and history of antibiotic administration. Routine CSF tests (including HBP) and routine serum tests (including CRP, TNF- $\alpha$, and PCT levels) were performed at hospital admission and at the start of effective treatment.

\section{Blood samples and laboratory analysis}

After patients were admitted to the hospital, early morning fasting venous blood was collected, placed in anticoagulated tubes, and centrifuged at $99 \mathrm{~g}$ and $22^{\circ} \mathrm{C}$ for $10 \mathrm{~min}$, and the supernatant was stored at $-80^{\circ} \mathrm{C}$. HBP levels in the CSF were determined using ELISA (Nanjing Xinfan Technology Co., Ltd., China). CRP was quantified by enzyme-linked fluorescence, PCT by latex immunoturbidimetric assay, and TNF- $\alpha$ levels by ELISA (Nanjing Xinfan Technology Co., Ltd.).

\section{Statistical analysis}

Data were analyzed using SPSS software system version 23.0 (SPSS, USA) and GraphPad Prism V.8.0 (GraphPad Software, USA). One-factor ANOVA was used to compare the three groups. Correlation analysis was performed using a Spearman test. The diagnostic ability of HBP in the CSF was assessed using the area under the receiver operating characteristic curve (AUC). The significance level was set at $\alpha=0.05$.

\section{Results}

\section{Baseline data}

The PM group included a total of 118 PM patients admitted to our hospital, the VM group included $110 \mathrm{VM}$ patients and the CON group included 80 children with suspected meningitis, which was ruled out. Vital signs among all groups were not significantly different (Table 1).

\section{Comparison of HBP levels in the CSF}

HBP of the PM group was $150.52 \pm 1.87 \mathrm{ng} / \mathrm{mL}$, of the VM group was $3.14 \pm 0.23 \mathrm{ng} / \mathrm{mL}$, and of the CON group was $0.33 \pm 0.02 \mathrm{ng} / \mathrm{mL}$. HBP levels were higher in the CSF of the PM group than in that of the CON and VM groups $(P<0.05$, Figure 1 ), indicating that HBP levels in the CSF could be used as a potential indicator for the diagnosis of PM.

White blood cell (WBC) count of the PM group was $2243 \pm 213 \mathrm{ng} / \mathrm{mL}$, of the VM group was $143 \pm 18.43 \mathrm{ng} /$ $\mathrm{mL}$, and of the CON group was $104 \pm 1.22 \mathrm{ng} / \mathrm{mL}$. CSFWBC levels were higher in the PM group than in the CON and VM groups $(P<0.05$, Figure 2$)$, indicating that CSF-WBC levels could be used as an indicator for the diagnosis of PM.

\section{Serum CRP, PCT, and TNF- $\alpha$ levels}

Serum CRP levels were significantly higher in the PM group than in the CON and VM groups $(P<0.05$, Figure 3$)$. Serum PCT levels and TNF- $\alpha$ levels in the PM group were also higher than those in the $\mathrm{CON}$ and VM groups $(P<0.05$, Figures 4 and 5, respectively).

Table 1. Baseline data.

\begin{tabular}{|c|c|c|c|c|}
\hline & Control group & Viral meningitis group & Purulent meningitis group & $\mathrm{P}$ value \\
\hline Case $(n)$ & 80 & 110 & 118 & \\
\hline Age (years) & $3.2 \pm 0.6$ & $3.7 \pm 0.5$ & $3.6 \pm 0.4$ & 0.667 \\
\hline Men/women (n) & $41 / 39$ & $63 / 47$ & $60 / 58$ & 0.784 \\
\hline Weight $(\mathrm{kg})$ & $18.9 \pm 2.1$ & $20.3 \pm 2.1$ & $20.1 \pm 2.2$ & 0.731 \\
\hline Heart rate (per min) & $89.7 \pm 1.6$ & $89.2 \pm 1.7$ & $88.4 \pm 1.6$ & 0.548 \\
\hline Respiratory rate (per min) & $20.2 \pm 1.1$ & $19.8 \pm 1.1$ & $21.0 \pm 1.3$ & 0.872 \\
\hline
\end{tabular}

Data are reported as means $\pm \mathrm{SD}$ or total number (ANOVA). 


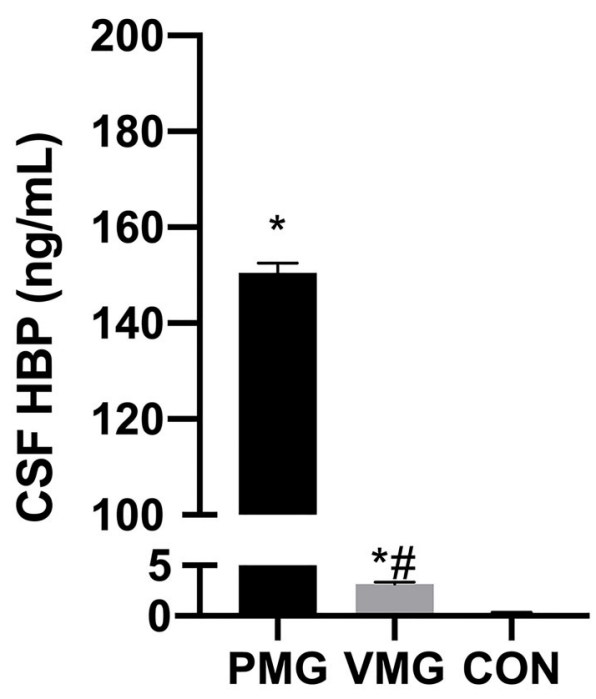

Figure 1. Comparison of heparin-binding protein (HBP) levels in the cerebrospinal fluid (CSF) of children. VMG: viral meningitis group; PMG: purulent meningitis group; CON: control group. Data are reported as means $\pm \mathrm{SD}$. ${ }^{*} \mathrm{P}<0.05$, vs $\mathrm{CON}$; ${ }^{\#} \mathrm{P}<0.05$, vs PMG (ANOVA).

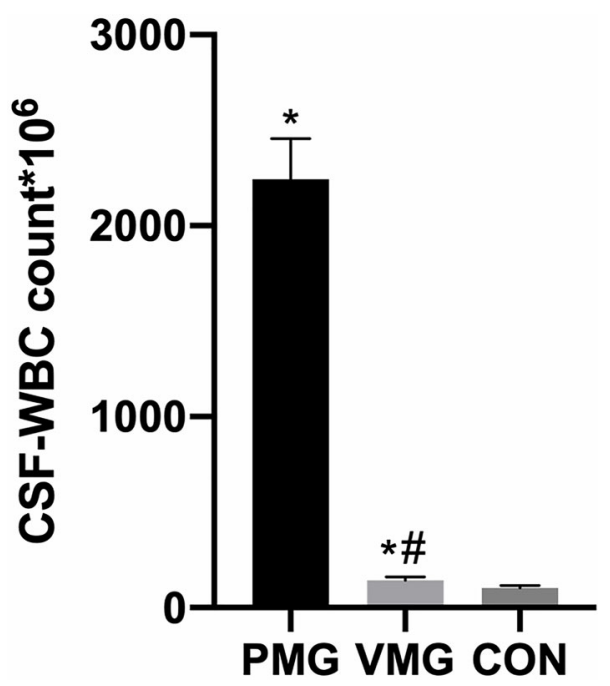

Figure 2. Comparison of cerebrospinal fluid white blood cell (CSF-WBC) count in the children. VMG: viral meningitis group; PMG: purulent meningitis group; CON: control group. Data are reported as means $\pm \mathrm{SD}$. ${ }^{*} \mathrm{P}<0.05$, vs $\mathrm{CON} ;{ }^{\#} \mathrm{P}<0.05$, vs $\mathrm{PMG}$ (ANOVA).

Diagnostic value of HBP, CRP, PCT, and TNF- $\alpha$ for PM

The diagnostic value of HBP, CRP, PCT, and TNF- $\alpha$ levels were assessed using ROC curves (Figure 6). The AUC of HBP was 0.8636 , with an optimal cutoff value of $\geqslant 54.7 \mathrm{ng} / \mathrm{mL}$, sensitivity of $98.3 \%$, and specificity of $88.3 \%$. The AUC of CRP was 0.6725 , with an optimal

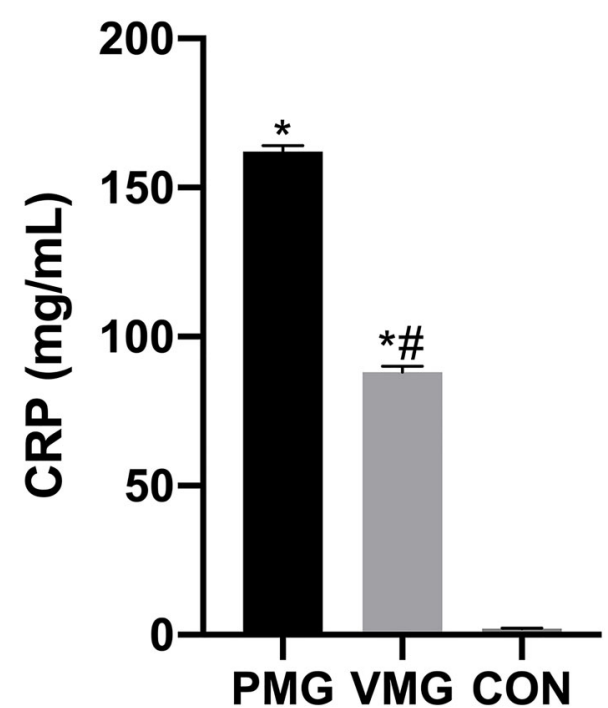

Figure 3. Comparison of serum C-reactive protein (CRP) levels of children. VMG: viral meningitis group; PMG: purulent meningitis group; CON: control group. Data are reported as means $\pm S D$. ${ }^{*} \mathrm{P}<0.05$, vs CON; ${ }^{~} \mathrm{P}<0.05$, vs $\mathrm{PMG}$ (ANOVA).

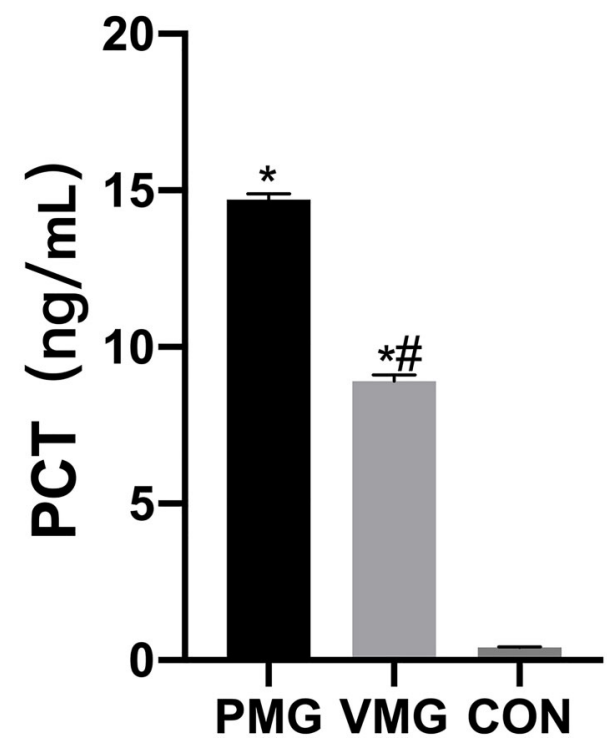

Figure 4. Comparison of serum procalcitonin (PCT) levels of children. VMG: viral meningitis group; PMG: purulent meningitis group; CON: control group. Data are reported as means $\pm S D$. ${ }^{*} \mathrm{P}<0.05$, vs CON; ${ }^{\mathrm{P}}<0.05$, vs $\mathrm{PM}$ (ANOVA).

cutoff value of $\geqslant 155.2 \mathrm{mg} / \mathrm{mL}$, sensitivity of $55.6 \%$, and specificity of $70.2 \%$. The AUC of PCT was 0.7316 , with an optimal cut-off value of $\geqslant 2.11 \mathrm{ng} / \mathrm{mL}$, sensitivity of $68.2 \%$, and specificity of $60.3 \%$. The AUC of TNF- $\alpha$ was 0.6995 , with an optimal cutoff value of $\geqslant 137.2 \mathrm{pg} / \mathrm{mL}$, sensitivity of $58.7 \%$, and specificity of $60.8 \%$. HBP levels in the CSF 
had the highest diagnostic value among these four indices (Table 2).

\section{Discussion}

$\mathrm{PM}$ is one of the most common causes of neonatal mortality, with survivors often suffering from neurological impairment with severe sequelae due to delayed diagnosis, which impacts their learning abilities and has longterm consequences (1). The key to the treatment and prognosis of $\mathrm{PM}$ is early diagnosis. Our findings showed that HBP, CSF-WBC count, CRP, PCT, and TNF- $\alpha$ levels were all elevated in the children with PM. Moreover, HBP was more accurate for the diagnosis of $\mathrm{PM}$ than traditional diagnostic indicators and could be used as an early indicator of PM.

As an inflammatory disease, PM is mainly caused by a combination of inflammatory factors and pathogenic

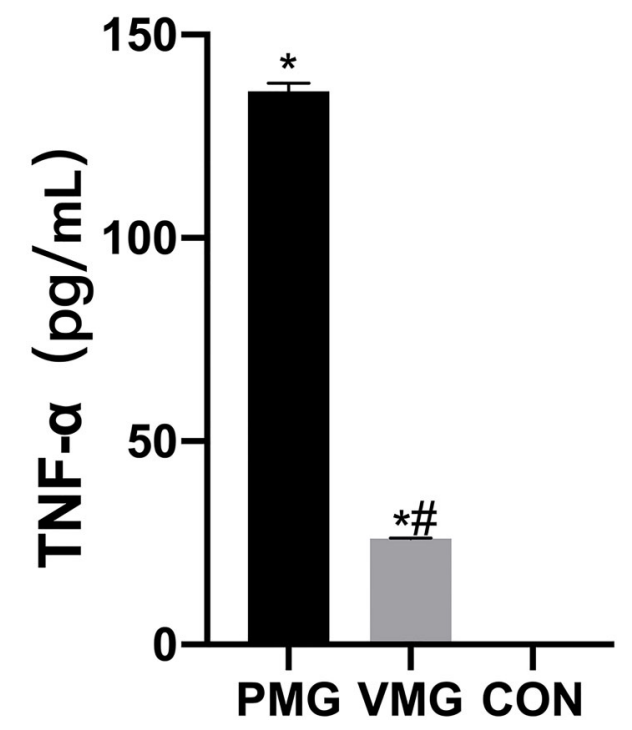

Figure 5. Comparison of serum tumor necrosis factor- $\alpha$ $(T N F-\alpha)$ levels of children. VMG: viral meningitis group; PMG: purulent meningitis group; CON: control group. Data are reported as means $\pm \mathrm{SD}$. ${ }^{*} \mathrm{P}<0.05$, vs $\mathrm{CON}$ group; ${ }^{\#} \mathrm{P}<0.05$, vs $\mathrm{PMG}$ (ANOVA). bacteria (12). Over the last decade, the rising misuse of antibiotics has resulted in higher incidences of antibiotic resistance in children (13), which has led to increased difficulty in the clinical diagnosis of PM, as well as VM.

As a serine protease, HBP acts as an important mediator of the inflammatory response (14). Evidence shows that HBP can be a good marker for the diagnosis of sepsis (15). Moreover, HBP tends to be elevated in patients with sepsis and accompanied by an exacerbation of the disease, compared to that in non-infected patients (16). It has been further shown (17) that elevated HBP levels ( $>30 \mathrm{ng} / \mathrm{mL}$ ) are present in $80 \%$ of patients prior to the occurrence of severe sepsis. The results of a metaanalysis (18) demonstrated that HBP can be used as a serum biomarker to identify bacterial infections. Kandil et al. (19) concluded that HBP is involved in severe bacterial infections and, therefore, can be used as a potential diagnostic marker and therapeutic target for sepsis. They also reported that elevated HBP levels in the CSF can distinguish patients with acute bacterial meningitis from those with other central nervous system infections (19).

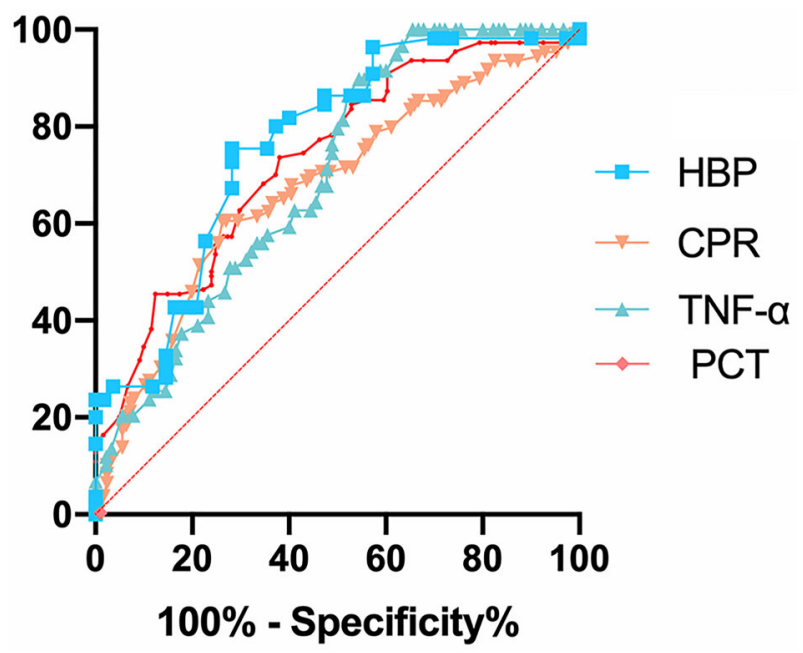

Figure 6. Receiver operating characteristic (ROC) curves for HBP, CRP, PCT, and TNF- $\alpha$ levels. HBP: heparin-binding protein; CRP: C-reactive protein; TNF- $\alpha$ : tumor necrosis factor- $\alpha$; PCT: procalcitonin.

Table 2. Levels of HBP, CRP, PCT, and TNF- $\alpha$ for the diagnosis of purulent meningitis.

\begin{tabular}{|c|c|c|c|c|c|c|}
\hline Diagnostic markers & Critical value & Sensitivity (\%) & Specificity (\%) & AUC & $95 \%$ AUC & $P$ value \\
\hline HBP (ng/mL) & 54.7 & 98.3 & 88.3 & 0.8636 & 0.8007 to 0.9264 & $<0.0001$ \\
\hline CRP $(\mathrm{mg} / \mathrm{mL})$ & 155.2 & 55.6 & 70.2 & 0.6725 & 0.6030 to 0.7421 & $<0.0001$ \\
\hline PCT (ng/mL) & 2.11 & 68.2 & 60.3 & 0.7316 & 0.6677 to 0.7956 & $<0.0001$ \\
\hline TNF- $\alpha(p g / m L)$ & 137.2 & 58.7 & 60.8 & 0.6995 & 0.6174 to 0.7816 & $<0.0001$ \\
\hline
\end{tabular}

AUC: area under the receiver operating characteristic curve; HBP: heparin-binding protein; CRP: C-reactive protein; PCT: procalcitonin; TNF- $\alpha$ : tumor necrosis factor- $\alpha$. 
However, this study only included a small number of cases. The present study showed a significant increase in HBP levels in the CSF of patients in the PM group compared to those in the VM and CON groups, which was consistent with the above results. In the strongest inflammatory response, leukocytes aggregated to the local site of infection, with enhanced monocyte activation and increased HBP secretion, resulting in elevated HBP levels in the CSF.

PCT, a newly discovered inflammatory factor, plays an important role in the diagnosis of infectious diseases (20). Serum PCT levels are relatively low under normal conditions. However, during bacterial infection, PCT expression increases (21). Davis et al. (22) showed that serum PCT levels in PM patients are higher than those in healthy controls $(P<0.05)$. Our results showed that serum PCT levels were higher in the PM group than in the CON and VM groups $(P<0.05)$. These findings suggested that inflammation can promote the secretion of PCT.

TNF- $\alpha$ is a common inflammatory factor, and under physiological conditions, its concentration is very low but

\section{References}

1. Zhao Z, Yu JL, Zhang HB, Li JH, Li ZK. Five-year multicenter study of clinical tests of neonatal purulent meningitis. Clin Pediatr (Phila) 2018; 57: 389-397, doi: 10.1177/0009922 817728699.

2. Randhawa E, Woytanowski J, Sibliss K, Sheffer I. Streptococcus pyogenes and invasive central nervous system infection. SAGE Open Med Case Rep 2018; 6: 2050313X 18775584, doi: 10.1177/2050313X18775584.

3. Kamoun F, Dowlut MB, Ameur SB, Sfaihi L, Mezghani S, Chabchoub I, et al. Neonatal purulent meningitis in southern Tunisia: Epidemiology, bacteriology, risk factors and prognosis. Fetal Pediatr Pathol 2015; 34: 233-240, doi: 10.3109/ 15513815.2015.1051252.

4. Srinivasan L, Kilpatrick L, Shah SS, Abbasi S, Harris MC. Cerebrospinal fluid cytokines in the diagnosis of bacterial meningitis in infants. Pediatr Res 2016; 80: 566-572, doi: 10.1038/pr.2016.117.

5. Oganesyan AN, Voropaeva EA, Mel'nikova AA, Mironov AY, Egorova EA, Urban YN, et al. Efficacy of laboratory methods of diagnostic of purulent bacterial meningitis [in Russian]. Klin Lab Diagn 2019; 64: 117-121, doi: 10.18821/08692084-2019-64-2-117-121.

6. Fisher J, Russell JA, Bentzer P, Parsons D, Secchia S, Mörgelin $M$, et al. Heparin-Binding Protein (HBP): a causative marker and potential target for heparin treatment of human sepsis-induced acute kidney injury. Shock 2017; 48: 313-320, doi: 10.1097/SHK.0000000000000862.

7. Linder A, Arnold R, Boyd JH, Zindovic M, Zindovic I, Lange $A$, et al. Heparin-binding protein measurement improves the prediction of severe infection with organ dysfunction in the emergency department. Crit Care Med 2015; 43: 23782386, doi: $10.1097 / \mathrm{CCM} .0000000000001265$.

8. Tverring J, Nielsen N, Dankiewicz J, Linder A, Kahn F, Åkesson P. Repeated measures of Heparin-binding protein (HBP) and procalcitonin during septic shock: biomarker increases dramatically during the onset of infection (23). TNF- $\alpha$ is a key player in the inflammatory response (24). In previous studies, TNF- $\alpha$ was shown to be significantly elevated in the serum of children with PM $(25,26)$. We have shown that serum TNF- $\alpha$ levels in children with PM are elevated, which is highly consistent with published results. TNF- $\alpha$ is considered to induce the production of several cytokines.

There are some limitations to this study. This was a single-center clinical study that included a small number of cases. Therefore, further large-scale multicenter studies are needed for validation. In addition, serum HBP levels in children with PM were not included in the study, and the association between serum HBP levels and the severity of $\mathrm{PM}$ remains to be explored.

In conclusion, the results of the present study showed that children with PM had higher HBP levels in their CSF than patients with VM or without meningitis. Therefore, HBP levels in the CSF can be used as an index for the early diagnosis of PM. kinetics and association with cardiovascular organ dysfunction. Intensive Care Med Exp 2020; 8: 51, doi: 10.1186/ s40635-020-00338-8.

9. Gautam N, Olofsson AM, Herwald H, Iversen LF, LundgrenAkerlund E, Hedqvist $P$, et al. Heparin-binding protein (HBP/ CAP37): a missing link in neutrophil-evoked alteration of vascular permeability. Nat Med 2001; 7: 1123-1127, doi: 10.1038/nm1001-1123.

10. Pereira HA, Shafer WM, Pohl J, Martin LE, Spitznagel JK. CAP37, a human neutrophil-derived chemotactic factor with monocyte specific activity. J Clin Invest 1990; 85: 14681476, doi: $10.1172 / \mathrm{JCl} 114593$.

11. Linder $A$, Akesson $P$, Brink $M$, Studahl $M$, Björck $L$, Christensson B. Heparin-binding protein: a diagnostic marker of acute bacterial meningitis. Crit Care Med 2011; 39: 812-817, doi: 10.1097/CCM.0b013e318206c396.

12. Cui W, Luo X, Zhang $Y$. Effects of purulent meningitis on the changes of matrix metalloproteinase-2 (MMP-2) and matrix metalloproteinase inhibitor-1 (TIMP-1) in cerebrospinal fluid of neonates. Pak J Pharm Sci 2019; 32: 2437-2441.

13. Hou $Y$, Zhang $X$, Hou X, Wu R, Wang Y, He X, et al. Rapid pathogen identification using a novel microarray-based assay with purulent meningitis in cerebrospinal fluid. Sci Rep 2018; 8: 15965, doi: 10.1038/s41598-018-34051-0.

14. Cheng Z, Yang YJ, Jing XG, Dai LL, Wang X, Jia LQ, et al. Diagnostic value of HBP, PCT combined with APACHE II score respectively in ventilator-associated pneumonia [in Chinese]. Zhonghua Yi Xue Za Zhi 2019; 99: 1698-1702, doi: 10.3760/cma.j.issn.0376-2491.2019.22.003.

15. Bentzer P, Fisher J, Kong HJ, Mörgelin M, Boyd JH, Walley $\mathrm{KR}$, et al. Heparin-binding protein is important for vascular leak in sepsis. Intensive Care Med Exp 2016; 4: 33, doi: 10.1186/s40635-016-0104-3.

16. Holub M, Džupová $\mathrm{O}$, Růžková $\mathrm{M}$, Stráníková $\mathrm{A}$, Bartáková E, Máca J, et al. Selected biomarkers correlate with the 
origin and severity of sepsis. Mediators Inflamm 2018; 2018 : 7028267, doi: 10.1155/2018/7028267.

17. Yang Y, Liu G, He Q, Shen J, Xu L, Zhu P, et al. A promising candidate: heparin-binding protein steps onto the stage of sepsis prediction. J Immunol Res 2019; 2019: 7515346, doi: 10.1155/2019/7515346.

18. Chen S, Zhang C, Hong G, Wang Q, Lian M. Meta-analysis of the diagnostic efficacy of heparin binding protein in adult sepsis [in Chinese]. Zhonghua Wei Zhong Bing Ji Jiu Yi Xue 2019; 31: 1330-1334, doi: 10.3760/cma.j.issn.2095-4352. 2019.11.004.

19. Kandil M, Khalil G, El-Attar E, Shehata G, Hassan S. Accuracy of heparin binding protein: as a new marker in prediction of acute bacterial meningitis. Braz $\mathrm{J}$ Microbiol 2018; 49: 213-219, doi: 10.1016/j.bjm.2018.05.007.

20. Hu L, Shi Q, Shi M, Liu R, Wang C. Diagnostic value of PCT and CRP for detecting serious bacterial infections in patients with fever of unknown origin: a systematic review and meta-analysis. Appl Immunohistochem $\mathrm{Mol}$ Morphol 2017; 25: e61-e69, doi: 10.1097/PAI.000000000 0000552.
21. Dymicka-Piekarska V, Wasiluk A. Procalcitonin (PCT), contemporary indicator of infection and inflammation [in Polish]. Postepy Hig Med Dosw (Online) 2015; 69: 723-728, doi: 10.5604/17322693.1158796.

22. Davis LE. Acute bacterial meningitis. Continuum (Minneap Minn) 2018; 24: 1264-1283.

23. Saha P, Smith A. TNF- $\alpha$ (Tumor Necrosis Factor- $\alpha$ ). Arterioscler Thromb Vasc Biol 2018; 38: 2542-2543, doi: 10.1161/ATVBAHA.118.311660.

24. Fernández-Ruiz M, Aguado JM. Risk of infection associated with anti-TNF- $\alpha$ therapy. Expert Rev Anti Infect Ther 2018; 16: 939-956, doi: 10.1080/14787210.2018.1544490.

25. Glimåker $\mathrm{M}$, Kragsbjerg $\mathrm{P}$, Forsgren $\mathrm{M}$, Olcén $\mathrm{P}$. Tumor necrosis factor-alpha (TNF alpha) in cerebrospinal fluid from patients with meningitis of different etiologies: high levels of TNF alpha indicate bacterial meningitis. J Infect Dis 1993; 167: 882-889, doi: 10.1093/infdis/167.4.882.

26. Liu Q, Gao Y, Zhang B, Sun F, Yang Q, Liu Y, et al. Cytokine profiles in cerebrospinal fluid of patients with meningitis at a tertiary general hospital in China. J Microbiol Immunol Infect 2020; 53: 216-224, doi: 10.1016/j.jmii.2018.08.019. 